\title{
Effect of Group Patient Education on Glycemic Control Among People Living with Type 2 Diabetes in Vietnam: A Randomized Controlled Single-Center Trial
}

Ho Thi Kim Thanh · Tran Manh Tien

Received: February 19, 2021 / Accepted: March 17, 2021 / Published online: April 11, 2021

(C) The Author(s) 2021

\begin{abstract}
Introduction: In low- to middle-income countries such as Vietnam, urgent measures are required to prevent and control type 2 diabetes and its complications. This study measured the effect of a 3-month patient education and selfmanagement intervention in a low-resource setting on diabetes knowledge and levels of blood glucose control.

Methods: This was a single-center randomized controlled study among adult outpatients with type 2 diabetes. Patients were randomly assigned to 3-month community intervention consisting of group education for type 2 diabetes knowledge, diet, exercise in combination with usual diabetes care, or to usual diabetes care alone (control). Diabetes knowledge was measured with a modified Michigan University Diabetes Knowledge Test (MDKT). Other study outcomes included change in mean HbA1c, fasting blood glucose (FBG), and systolic blood pressure (SBP).
\end{abstract}

Supplementary Information The online version contains supplementary material available at https:// doi.org/10.1007/s13300-021-01052-8.

H. T. K. Thanh $(\varangle) \cdot$ T. M. Tien

Hanoi Medical University, Vietnam National

Geriatric Hospital, 1 Ton That Tung Street, Dong Da,

Hanoi, Vietnam

e-mail: hokimthanh@hmu.edu.vn
Results: A total of 364 patients were randomized, 182 to the intervention group and 182 to control. The two groups were similar regarding main baseline characteristics. The male/female ratio was $45.1 \% / 54.9 \%$ and mean age was $62.2 \pm 9.3$ years. Approximately half the patients (48.1\%) were overweight and $15.7 \%$ were obese, mean baseline HbA1c was $8.21 \pm 1.92 \%$, and only $29.9 \%$ of participants had a baseline HbA1c $<7.0 \%$. At baseline, diabetes knowledge was "very poor" or "poor" in $63.7 \%$ of patients. After a 3-month follow-up, the proportion achieving the target MDKT score increased from $37.4 \%$ to $81.3 \%$ in the intervention group and from $35.2 \%$ to $51.7 \%$ in the control (between-group difference $P<0.001$ ). The estimate (SD) of the difference between intervention and control groups was -1.63 (2.16), 95\% CI -2.07 to -1.18 . Mean changes from baseline HbA1c were $-0.54 \pm 1.41 \%$ and $-0.18 \pm 1.33 \%$ in the intervention and control groups, respectively $(P=0.012)$. Among those with poor glycemic control (HbA1c $\geq 7 \%$ ) at baseline, mean changes at 3 months were $-0.80 \pm 1.52 \%$ vs $0.41 \pm 1.47 \%$, respectively, $\quad(P=0.013)$. Statistically significant decreases in FBG and SBP were also observed in the intervention group at 3 months, but not in the control group. Multivariate analysis revealed the variables with the strongest influence on blood glucose control at 3 months were study group, baseline MDKT score, diabetes duration, and baseline HbA1c (all $P \leq 0.05$ ). 
Conclusion: Provision of a structured educational program to Vietnamese people living with type 2 diabetes is effective at improving disease knowledge and is associated with better glycemic control. Larger and longer-term studies are now warranted to confirm these findings.

Trial Registration: This trial was retrospectively registered on 27 May 2020 through the https://clinicaltrials.gov site with the following identifier: NCT04403841

Keywords: Developing countries; Diabetes mellitus type 2; Glycemic control; Patient education; Self-management; Vietnam

\section{Key Summary Points}

\section{Why carry out this study?}

A challenge in low- to middle-income countries such as Vietnam is to implement effective, affordable, and sustainable interventions to reduce the rising prevalence of type 2 diabetes and its complications.

Few data are available on the value of education and lifestyle intervention in type 2 diabetes outside of developed countries.

This was addressed in the current study which evaluated the effects of a patient education and self-management intervention as add-on to usual diabetes care on diabetes knowledge and blood glucose control parameters in Vietnamese patients with type 2 diabetes.

\section{What was learned from the study?}

A low level of diabetes knowledge was confirmed among the general population as well as overall poor blood glucose control.
After only 3 months, patients randomized to three 45-min sessions of additional education and support achieved significantly improved disease awareness and blood glucose control compared with those receiving usual diabetes care alone, particularly in those whose HbA1c was not controlled at baseline.

Structured, group-based educational intervention for people with type 2 diabetes may offer an effective and affordable means of increasing disease knowledge and improving levels of blood glucose control in low- to middle-income countries.

\section{DIGITAL FEATURES}

This article is published with digital features, including a summary slide, to facilitate understanding of the article. To view digital features for this article go to https://doi.org/10.6084/ m9.figshare.14222459.

\section{INTRODUCTION}

In Vietnam and other low- to middle-income countries, the rapid transition from an agricultural to more industrial economy with associated changes in lifestyle and nutrition habits has been accompanied by an increase in the prevalence of non-communicable diseases such as type 2 diabetes [1-6]. Estimates based on data from over 1600 individuals participating in community diabetes screening programs over the period 2011-2013 reported a diabetes prevalence of $6.0 \%$ and prediabetes prevalence of $13.5 \%$ [7]. These rates are projected to rise to $7.0 \%$ and $15.7 \%$, respectively, by 2035 as a result of population aging [7].

The challenge in these lower-income countries is to establish effective and affordable interventions to prevent the development of type 2 diabetes and its complications that can be successfully accessed, implemented, and 
sustained. A number of systematic reviews and meta-analyses have demonstrated that compared with standard care alone, diabetes selfmanagement education (DSME) programs are effective at improving glycemic control, body mass index, and other cardiovascular risk factors in a range of different populations, regardless of the duration since type 2 diabetes diagnosis [8-12]. In particular, group-based programs with active participation appear to provide the greatest benefits. A recent review of 21 studies from the Asian Western Pacific region including Vietnam confirmed these findings, but highlighted an urgent need to develop culturally appropriate DSME and ensure that all communities have access to such programs [10]. Studies conducted in different parts of the world have suggested that many patients lack the skills to self-manage their condition $[13,14]$. Vietnam is no exception, with a low level of diabetes knowledge among the general population aged 40-64 years, and significantly lower awareness in rural areas compared with urban areas [14]. Community-based programs, providing culturally appropriate diabetes health education, offer a practical, relatively low-resource solution [15-17]. One such program is the Ngaydautien project (https://ngaydautien. vn), which was launched in 2016 in collaboration with the Ministry of Health, Vietnam National Heart Association, Vietnam Association of Diabetes \& Endocrinology, and the private sector. The main goal of this project is to improve control of type 2 diabetes and hypertension through education of patients, providing them with the skills to self-manage their condition. While a few Vietnam-based studies have examined methods of promoting health to patients with diabetes from a nursing perspective $[18,19]$, there is little research on patients' knowledge of type 2 diabetes and the impact that this has on diabetes management.

The aim of the current study was therefore to evaluate the effects of a patient education and self-management intervention as add-on to usual diabetes care in a low-resource setting on diabetes knowledge and blood glucose control parameters in Vietnamese patients with type 2 diabetes.

\section{METHODS}

\section{Study Design}

This was a single-center randomized controlled study conducted between August 2017 and July 2018 among adults with type 2 diabetes in Vietnam. The study protocol was approved by the independent local Institutional Review Board of Thach That General Hospital and Hanoi Medical University, Hanoi. The trial was registered through the https://clinicaltrials.gov site with the following identifier: NCT04403841. The trial was performed in accordance with the Helsinki Declaration of 1964 and its later amendments. Written informed consent for participation in this study was obtained from all participants.

Male and female outpatients with a diagnosis of type 2 diabetes treated at Thach That General Hospital were screened for study eligibility. Type 2 diabetes diagnosis was based on the criteria of the American Diabetes Association (ADA) [20] as recommended by the Vietnam Ministry of Health: fasting blood glucose $\geq 126 \mathrm{mg} / \mathrm{dL}(7.0 \mathrm{mmol} / \mathrm{L})$; blood glucose after a $2 \mathrm{~h}, 75 \mathrm{~g}$ oral glucose tolerance test $\geq 200 \mathrm{mg} / \mathrm{dL}(11.1 \mathrm{mmol} / \mathrm{L})$; or any blood glucose value $\geq 200 \mathrm{mg} / \mathrm{dL} \quad(11.1 \mathrm{mmol} / \mathrm{L})$ accompanied by typical conditions of hyperglycemia. Random sampling was used among nearly 1000 patients with diabetes treated monthly in Thach That Hospital, to ensure that the participants were representative of the whole population. Inclusion criteria were patients diagnosed with type 2 diabetes as defined above; aged $40-80$ years old; ability to attend monthly clinic visits; and signed informed consent. All antidiabetes treatments were permitted including insulin. Exclusion criteria included a diagnosis of mental or neurological diseases that could interfere with the ability to comply with study procedures; pregnancy; lactation; known drug or alcohol dependence; and requirement for a change in antidiabetes treatment over the study period. The latter was required to ensure that any changes in HbA1c during the study were due to 
the educational intervention and not changes in treatment.

\section{Study Interventions and Outcomes}

Patients meeting the inclusion criteria were randomly allocated in a 1:1 ratio to either a community intervention or to usual diabetes care alone (control group) for a period of 3 months. Randomization was based on a single sequence of random assignments (simple randomization). The study was designed and powered to show the superiority of the community intervention over usual diabetes care alone.

Usual diabetes care was consistent with the ADA guidelines [15] and comprised standard dietary and exercise advice in addition to antidiabetes treatment. The community intervention was delivered as part of the Ngaydautien project (https://ngaydautien.vn/gioi-thieungay-dau-tien), a collaborative effort between the Vietnam government and national diabetes and hypertension societies to improve disease self-management. At the inclusion visit, individuals were divided into small groups of 5-10 patients according to their level of awareness, assessed using the modified Michigan University Diabetes Knowledge Test (MDKT) [21, 22]. The typical characteristics of patients in each group and the corresponding educational goals are illustrated in Supplementary Material Table 1. The intervention consisted of group education on type 2 diabetes including, in addition to usual diabetes care, information on diet, exercise, drug therapy, and adherence. This was provided in the form of three 45-min sessions led by trained medical staff educators and is easily performed at any diabetes clinic or hospital outpatient setting. The overall aim of the sessions was to increase patients' knowledge and self-awareness and thus enable them to take charge of their own diabetes self-management. Regardless of disease awareness group, the focus of the individual group sessions was on patient collaboration and exchange of knowledge and information. The educators were trained to communicate with patients in a constructive and sympathetic manner to encourage changes in the patients' health-related behavior and reduce their risk of future type 2 diabetes-related complications. Each education session consisted of five steps: (1) introduction to group members; (2) patient interviews to determine their knowledge on type 2 diabetes, nutrition, exercise, and medication adherence; (3) provision of information, the theme of which changed each month, e.g., diet and balanced nutrition (month 1 ), how to maintain a suitable exercise program (month 2 ), and use of type 2 diabetes medication (month 3); (4) question and answers; and (5) provision of the patient toolkit and scheduling of next appointment. The patient toolkit was available as part of the Ngaydautien project, which included a patient leaflet, guidebook, and instructions on how to access the program via www.ngaydautien.vn. Each patient attended the group education monthly, over three consecutive months.

\section{Primary Outcome: Disease Awareness}

All patients completed a modified MDKT [21] at baseline and at the end of the 3-month trial. The MDKT was selected as it has been widely used in diverse populations [23-28], and because it is a quick and low-cost method of assessing general knowledge of diabetes and diabetes self-care that has previously demonstrated appropriate reliability and validity $[21,22]$. The 23 -item original questionnaire was translated into Vietnamese and adapted as required on the basis of a pilot test performed in 10 people with type 2 diabetes, which resulted in one question being removed. The modified questionnaire therefore consisted of 22 statements with multiple choice answers with 1 point awarded for each correct answer (Supplementary Material, Document 1). Patients who answered more than $50 \%$ of the questions correctly were considered to pass the knowledge test, and patients who answered less than 50\% of the questions correctly were considered to fail. The proportion of successful patients (i.e., with MDKT total score $\geq 11$ ) was the study primary outcome. The four subcategories of the total score considered to assess patients' level of 
awareness were $<5.5$ (very poor), 5.5 to $<11$ (poor), $11 \leq 16.5$ (average), and $\geq 16.5$ (good).

\section{Clinical Outcomes}

Clinical outcomes were measured at baseline and after the 3-month follow-up.

The primary clinical outcome was change in HbA1c level. Two categories of HbA1c level were also defined for the analysis: controlled and uncontrolled, $<7 \%$ and $\geq 7 \%$, based on guideline-recommended target HbA1c levels at the time of the study [29-31].

Secondary outcomes included laboratory parameters (fasting blood glucose [FPG], total cholesterol, HDL, LDL, triglycerides), BMI, and blood pressure. Hypertension was defined according to Vietnamese guidelines (SBP $\geq 140 \mathrm{mmHg}$ and/or $\mathrm{DBP}>90 \mathrm{mmHg}$ ) [32].

Classification of BMI level was based on World Health Organization (WHO) criteria for the Asia-Pacific region: $18.5-22.9 \mathrm{mg} / \mathrm{kg}^{2}$ (normal weight), $23-24.9 \mathrm{~kg} / \mathrm{m}^{2}$ (overweight), $25-29.9 \mathrm{~kg} / \mathrm{m}^{2} \quad$ (obesity level 1$), \geq 30 \mathrm{~kg} / \mathrm{m}^{2}$ (obesity level 2) [33].

\section{Statistical Analysis}

Sample size estimation was calculated on the basis of the primary outcome and expressed as the proportion of patients with successful test completion after 3 months. The sample size was calculated with SAS ${ }^{\circledR}$ software 9.4 (SAS Institute, Cary, North Carolina, USA) for a superiority design based on a one-sided Pearson chisquare test [34].

The value assumed for the outcome in the control group was $43 \%$ according to a previous study undertaken in Vietnam [35]. It was therefore estimated that 270 participants would be needed to detect approximately a $20 \%$ improvement with an alpha of 0.025 and a power of $80.0 \%$. With a $20 \%$ loss to follow-up anticipated, a total of 340 participants (170 per group) were targeted.

Results are presented as means and standard deviations (SD) for continuous data and frequencies and percentages for categorical data. A chi-square test was used for between-group comparisons of categorical variables. To compare values of continuous variables at the same time point between the control and intervention groups the two-sample $t$ test was used. The Wilcoxon rank sum test was used for MDKT, which did not exhibit a normal distribution. Changes at 3 months were compared to the baseline values with the paired $t$ test (or Wilcoxon paired test for the MDKT).

Univariate logistic regression analysis was used to identify potential factors influencing blood glucose control in patients with uncontrolled HbA1c at baseline based on Wald chisquare test $P$ values (PROC LOGISTIC under SAS 9.4). All variables testing significant in univariate analysis were included in the multivariate logistic regression analysis using a stepwise selection procedure where a significance level of 0.2 was required to allow a variable to enter the model, and a significance level of 0.05 was required for a variable to stay in the model. In this manner, only factors independently significant at the 5\% threshold were retained. Odds ratios and their 95\% CI and associated Wald chi-square test $P$ values were calculated. Statistical significance was assumed when $P<0.05$. SAS ${ }^{\circledR}$ (SAS Institute, Cary, North Carolina, USA) software 9.4. was used for statistical analyses.

\section{RESULTS}

\section{Demography and Baseline Characteristics}

A total of 405 patients met the inclusion criteria and were randomized to community intervention or to the control group. A total of 19 patients who did not come to the hospital monthly or moved to another location and 22 patients who changed their antidiabetes medications during the study period were excluded from the analysis. As a result, 364 patients, 182 in the intervention group and 182 in the control group, were included in the analysis (Fig. 1).

Demographic data and clinical characteristics were similar between the control and intervention groups with no statistically significant differences and are summarized in Table 1. 


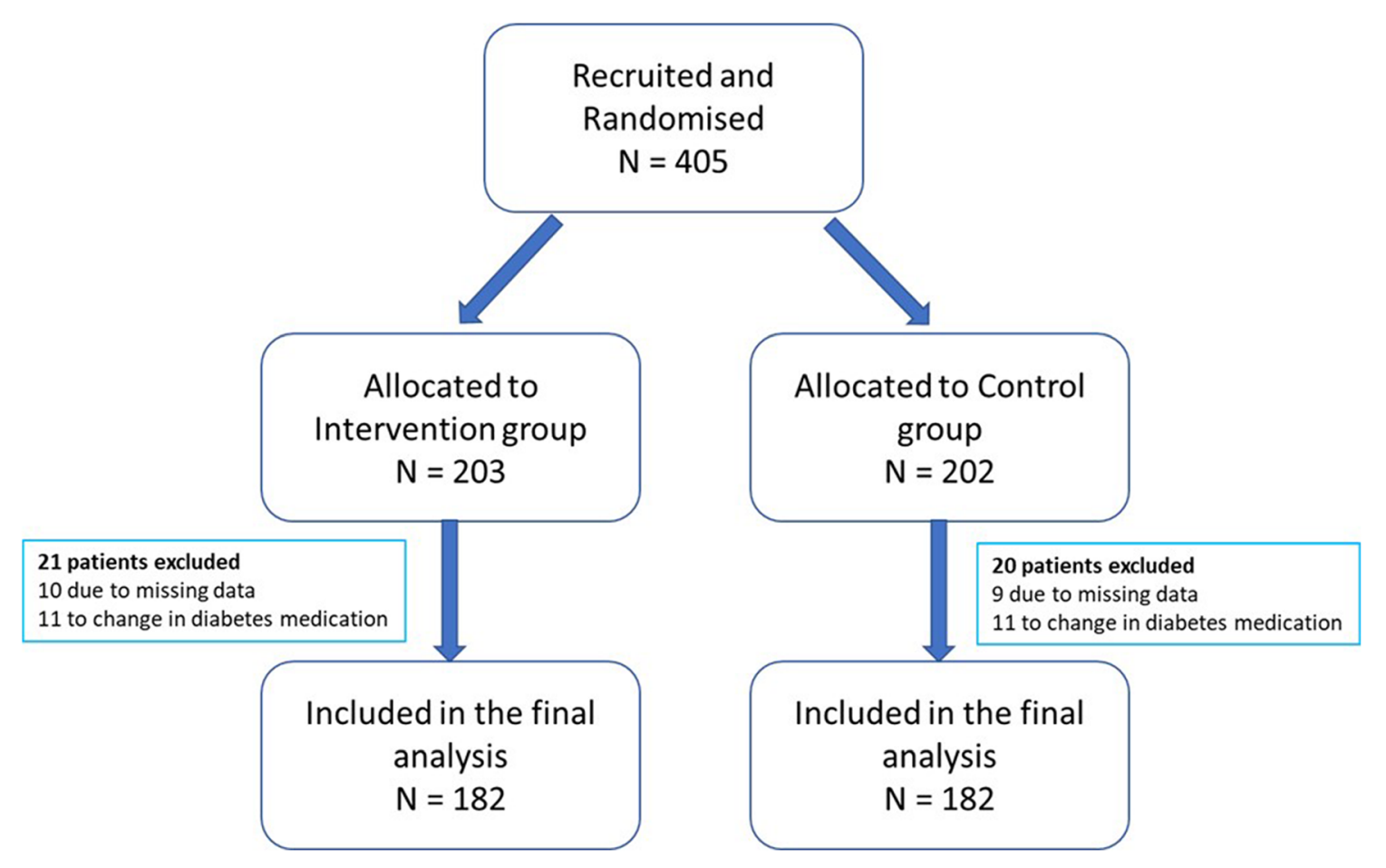

Fig. 1 Flow of patients through the study

Baseline macrovascular complications included coronary artery disease (one angina pectoris and one myocardial infarction, both in the control group), stroke (four individuals, all in the control group), and peripheral arterial disease (four cases of diabetic foot affecting two patients in each group). Baseline microvascular complications included retinopathy (five cases, two in the control group and three in the education group), and neuropathy (two cases both in the control group). Nephropathy was not evaluated in this study.

Mean MDKT baseline score was $7.70 \pm 2.98$, with a majority of patients having a very poor or poor knowledge of their disease $(63.7 \%)$. The baseline rate of successful test completion (36.3\%) was comparable in both groups.

Mean baseline $\mathrm{HbA} 1 \mathrm{c}$ was $8.21 \pm 1.92 \%$. The mean value was numerically lower in the intervention group $(8.09 \pm 1.85 \%)$ than in the control group $(8.32 \pm 2.09 \%)$. Less than one third of participants had a baseline HbA1c < $7.0 \%(29.9 \%)$ and this proportion was comparable in both groups: $30.8 \%$ in the control group and $29.1 \%$ in the intervention group.
At baseline, patients were receiving a range of antidiabetes medications including metformin, sulfonylureas or fixed-dose combinations thereof, acarbose, and insulins. The proportion of patients receiving the different treatments was similar between the two groups with the exception of a greater number of patients on insulin in the control group (32 vs 23 patients) and a greater number of patients on metformin alone in the intervention group (12 vs 22 patients); neither of these differences reached statistical significance (Table 2). The doses of antidiabetes medications were also evenly distributed between the control and intervention groups (Supplementary Material Table 2). As part of the study inclusion criteria no changes in antidiabetes treatments or dosing were permitted during the study.

\section{Michigan Diabetes Knowledge Test}

Mean MDKT values increased in both groups over the 3-month study period, from $7.86 \pm 2.91$ to $10.52 \pm 2.08$ in the intervention group (a mean improvement in score of 
Table 1 Baseline demographic and clinical characteristics

\begin{tabular}{|c|c|c|c|c|}
\hline Baseline characteristics & $\begin{array}{l}\text { Control } \\
(N=182)\end{array}$ & $\begin{array}{l}\text { Intervention } \\
(N=182)\end{array}$ & $\begin{array}{l}\text { All } \\
(N=364)\end{array}$ & $\begin{array}{l}P \text { value } \\
\text { (between- } \\
\text { group } \\
\text { comparison) }\end{array}$ \\
\hline Mean age $( \pm S D)$ (years) & $62.9 \pm 9.4$ & $61.5 \pm 9.2$ & $62.2 \pm 9.3$ & $0.148^{\mathrm{a}}$ \\
\hline Gender ( $\%$ female $)$ & 54.4 & 55.5 & 54.9 & $0.833^{\mathrm{b}}$ \\
\hline \multicolumn{5}{|l|}{ Duration of disease ( $\%$ in each category) } \\
\hline$<1$ year & 10.4 & 11.0 & 10.7 & \multirow[t]{3}{*}{$0.297^{\mathrm{b}}$} \\
\hline $1-5$ years & 51.1 & 58.2 & 54.7 & \\
\hline$>5$ years & 38.5 & 30.8 & 34.6 & \\
\hline Mean duration (years) & $4.4 \pm 2.7$ & $4.4 \pm 2.6$ & $4.4 \pm 2.7$ & $0.873^{\mathrm{a}}$ \\
\hline Family history of diabetes (\% yes) & 30.2 & 27.5 & 28.8 & $0.732^{c}$ \\
\hline Regular tobacco smoking (\% yes) & 15.9 & 13.2 & 14.6 & $0.756^{\mathrm{b}}$ \\
\hline Regular alcohol consumption (\% yes) & 22.5 & 19.8 & 21.2 & $0.206^{\mathrm{c}}$ \\
\hline \multicolumn{5}{|l|}{ Comorbidities (\% with comorbidity) } \\
\hline None & 43.4 & 48.9 & 46.2 & \multirow[t]{3}{*}{$0.493^{\mathrm{b}}$} \\
\hline Arterial hypertension & 34.6 & 34.1 & 34.3 & \\
\hline Lipid disorders & 31.9 & 28.6 & 30.2 & \\
\hline \multicolumn{4}{|l|}{ Physical activity (\% performing) } & \multirow[t]{4}{*}{$0.560^{\mathrm{b}}$} \\
\hline None & 15.9 & 12.6 & 14.3 & \\
\hline$<3$ times/week & 18.1 & 16.5 & 17.3 & \\
\hline Regularly & 65.9 & 70.9 & 68.4 & \\
\hline \multicolumn{4}{|c|}{ Level of type 2 diabetes awareness ( $\%$ in each category) } & \multirow[t]{4}{*}{$0.338^{\mathrm{b}}$} \\
\hline Very poor & 28.0 & 21.4 & 24.7 & \\
\hline Poor & 36.8 & 41.2 & 39.0 & \\
\hline Average & 35.2 & 37.4 & 36.3 & \\
\hline MDKT mean score $( \pm S D)$ & $7.53 \pm 2.98$ & $7.86 \pm 2.91$ & $7.70 \pm 2.98$ & $0.286^{\mathrm{a}}$ \\
\hline Success $(\%)$ & 35.2 & 37.4 & 36.3 & \multirow[t]{2}{*}{$0.663^{\mathrm{b}}$} \\
\hline Failure (\%) & 64.8 & 62.6 & 63.7 & \\
\hline Mean $\mathrm{HbA1c}( \pm \mathrm{SD})$ & $8.32 \pm 1.99$ & $8.09 \pm 1.85$ & $8.21 \pm 1.92$ & $0.259^{\mathrm{a}}$ \\
\hline$\%$ of $\mathrm{HbA} 1 \mathrm{c}<7 \%$ & 30.8 & 29.1 & 29.9 & \multirow[t]{2}{*}{$0.731^{\mathrm{b}}$} \\
\hline$\%$ of $\mathrm{HbAlc} \geq 7 \%$ & 69.2 & 70.9 & 70.1 & \\
\hline Mean fasting blood glucose $(\mathrm{mmol} / \mathrm{L})$ & $8.72 \pm 2.66$ & $8.95 \pm 2.82$ & $8.83 \pm 2.74$ & $0.432^{\mathrm{a}}$ \\
\hline BMI $\left(\mathrm{kg} / \mathrm{m}^{2}\right)$ mean $( \pm \mathrm{SD})$ & $22.9 \pm 2.9$ & $22.7 \pm 2.8$ & $22.8 \pm 2.8$ & $0.458^{\mathrm{a}}$ \\
\hline $18.5-22.9(n, \%)$ & $11(6.0)$ & $8(4.4)$ & $19(5.2)$ & $0.160^{\mathrm{b}}$ \\
\hline
\end{tabular}


Table 1 continued

\begin{tabular}{lllll}
\hline Baseline characteristics & $\begin{array}{l}\text { Control } \\
(\boldsymbol{N}=\mathbf{1 8 2})\end{array}$ & $\begin{array}{l}\text { Intervention } \\
(\boldsymbol{N}=\mathbf{1 8 2})\end{array}$ & $\begin{array}{l}\text { All } \\
(\boldsymbol{N}=\mathbf{3 6 4})\end{array}$ & $\begin{array}{l}\boldsymbol{P} \text { value } \\
\text { (between- } \\
\text { group } \\
\text { comparison) }\end{array}$ \\
\hline $23.0-24.9(n, \%)$ & $76(41.8)$ & $94(51.7)$ & $170(46.7)$ & \\
25.0 to $\geq 30.0(n, \%)$ & $95(52.2)$ & $80(44.0)$ & $175(48.1)$ & \\
Systolic blood pressure $(\mathrm{mmHg})$ & $124.5 \pm 17.4$ & $123.5 \pm 15.5$ & $124.0 \pm 16.5$ & $0.579^{\mathrm{a}}$ \\
$\begin{array}{l}\text { Diastolic blood pressure }(\mathrm{mmHg}) \\
\text { SBP } \geq 140 \mathrm{mmHg} \text { and/or DBP }>90 \mathrm{mmHg} \text { at } \\
\quad \text { the visit }(n, \%)\end{array}$ & $52(28.6)$ & $34(18.7)$ & $86(23.6)$ & $0.026^{\mathrm{b}}$ \\
$\begin{array}{l}\text { Total cholesterol }(\mathrm{mmol} / \mathrm{L}) \\
\text { Triglycerides }(\mathrm{mmol} / \mathrm{L})\end{array}$ & $5.1 \pm 1.3$ & $5.1 \pm 1.3$ & $5.1 \pm 1.3$ & $0.834^{\mathrm{a}}$ \\
\hline
\end{tabular}

${ }^{a}$ Student's $t$ test

b Chi-square test

${ }^{c}$ Fisher's exact test

Table 2 Most common antidiabetes treatments prescribed at baseline

\begin{tabular}{llcc}
\hline Treatment & \multicolumn{2}{l}{ Number (\%) patients } & \\
\cline { 2 - 4 } & Control & Intervention & $\boldsymbol{P ~ v a l u e ~}^{\mathbf{a}}$ \\
\hline Oral antidiabetes agents & $99(54.4)$ & $99(54.4)$ & 1.00 \\
Metformin + glibenclamide & $20(11.0)$ & $17(9.3)$ & 0.60 \\
Metformin + gliclazide & $12(6.6)$ & $22(12.1)$ & 0.07 \\
Metformin alone & $12(6.6)$ & $11(6.0)$ & 0.83 \\
Acarbose alone & $32(17.6)$ & $23(12.6)$ & 0.19 \\
Insulin-based treatment & $150(82.4)$ & $159(87.4)$ & \\
Non-insulin-based treatment &
\end{tabular}

${ }^{a}$ Chi-square test

$2.66 \pm 2.49)$ and from $7.53 \pm 2.98$ to $8.57 \pm 2.86$ in the control group (a mean improvement in score of $1.03 \pm 1.78$ ) (Table 3). The improvement was significant in both groups (intra-group comparison $P<0.001$ ) and significantly more pronounced in the intervention group (between group comparison $P<0.001)$. The estimate (SD) of the difference between the intervention and control groups was - 1.63 (2.16), 95\% confidence interval (CI)
-2.07 to -1.18 . MDKT values were also significantly increased in both control and intervention groups in insulin-treated and noninsulin-treated subgroups, and in subgroups with $\mathrm{HbA} 1 \mathrm{c}<7 \%$ as well as $\geq 7 \%$ at baseline (Table 3). In all these subgroups, the improvement in MDKT values was significantly greater in the intervention group (between group comparison $P<0.001 ; P=0.026$ for comparison in insulin-treated subgroup). 
Table 3 Change in main study parameters from baseline to 3 months

\begin{tabular}{|c|c|c|c|c|}
\hline Baseline & 3 months & $\begin{array}{l}\text { Change } \\
\text { from } \\
\text { baseline }\end{array}$ & $\begin{array}{l}P \text { value } \\
\text { (intra- } \\
\text { group } \\
\text { comparison) }^{a}\end{array}$ & $\begin{array}{l}P \text { value } \\
\text { (between- } \\
\text { group } \\
\text { comparison) }\end{array}$ \\
\hline
\end{tabular}

Michigan total score

Total population $(n=364)$

\begin{tabular}{|c|c|c|c|c|c|}
\hline Control & $7.53 \pm 2.98$ & $8.57 \pm 2.86$ & $1.03 \pm 1.78$ & $<0.001$ & $<0.001$ \\
\hline Intervention & $7.86 \pm 2.91$ & $10.52 \pm 2.08$ & $2.66 \pm 2.49$ & $<0.001$ & \\
\hline \multicolumn{6}{|c|}{ Insulin-treated subgroup $(n=55)$} \\
\hline Control & $7.44 \pm 2.91$ & $8.56 \pm 2.83$ & $1.13 \pm 1.62$ & $<0.001$ & \multirow[t]{2}{*}{0.02} \\
\hline Intervention & $8.09 \pm 2.56$ & $10.48 \pm 2.23$ & $2.39 \pm 2.31$ & $<0.001$ & \\
\hline \multicolumn{6}{|c|}{ Non-insulin-treated subgroup $(n=309)$} \\
\hline Control & $7.55 \pm 3.01$ & $8.57 \pm 2.87$ & $1.01 \pm 1.81$ & $<0.001$ & \multirow[t]{2}{*}{$<0.001$} \\
\hline Intervention & $7.83 \pm 2.96$ & $10.53 \pm 2.07$ & $2.70 \pm 2.52$ & $<0.001$ & \\
\hline \multicolumn{6}{|c|}{ HbAlc $<7 \%$ at baseline $(n=109)$} \\
\hline Control & $7.11 \pm 2.77$ & $8.21 \pm 2.85$ & $1.11 \pm 1.84$ & $<0.001$ & \multirow[t]{2}{*}{$<0.001$} \\
\hline Intervention & $7.77 \pm 2.45$ & $10.72 \pm 1.74$ & $2.94 \pm 2.33$ & $<0.001$ & \\
\hline \multicolumn{6}{|c|}{ HbAlc $\geq 7 \%$ at baseline $(n=255)$} \\
\hline Control & $7.72 \pm 3.06$ & $8.72 \pm 2.86$ & $1.00 \pm 1.76$ & $<0.001$ & \multirow[t]{2}{*}{$<0.001$} \\
\hline Intervention & $7.90 \pm 3.08$ & $10.44 \pm 2.21$ & $2.54 \pm 2.56$ & $<0.001$ & \\
\hline
\end{tabular}

HbA1c

Total population $(n=364)$

$\begin{array}{lccccc}\text { Control } & 8.32 \pm 1.99 & 8.15 \pm 1.80 & -0.18 \pm 1.33 & 0.077 & 0.012 \\ \text { Intervention } & 8.09 \pm 1.85 & 7.56 \pm 1.64 & -0.54 \pm 1.41 & 0.001 \\ \text { Insulin-treated subgroup }(n=55) & & & & \\ \text { Control } & 9.70 \pm 2.49 & 9.54 \pm 2.39 & -0.16 \pm 1.36 & 0.521 & 0.020 \\ \text { Intervention } & 9.97 \pm 2.17 & 8.60 \pm 2.32 & -1.37 \pm 2.08 & <0.005 \\ \text { Non-insulin-treated subgroup }(n=309) & & & \\ \text { Control } & 8.03 \pm 1.74 & 7.85 \pm 1.50 & -0.18 \pm 1.33 & 0.10 & 0.102 \\ \text { Intervention } & 7.82 \pm 1.64 & 7.40 \pm 1.47 & -0.42 \pm 1.25 & <0.001\end{array}$

Fasting plasma glucose

$\begin{array}{llcccc}\text { Control } & 8.72 \pm 2.66 & 8.49 \pm 2.53 & -0.23 \pm 2.14 & 0.143 & 0.001 \\ \text { Intervention } & 8.95 \pm 2.82 & 7.90 \pm 2.03 & -1.04 \pm 2.57 & <0.001 & \end{array}$


Table 3 continued

\begin{tabular}{|c|c|c|c|c|c|}
\hline & Baseline & 3 months & $\begin{array}{l}\text { Change } \\
\text { from } \\
\text { baseline }\end{array}$ & $\begin{array}{l}P \text { value } \\
\text { (intra- } \\
\text { group } \\
\text { comparison) }\end{array}$ & $\begin{array}{l}P \text { value } \\
\text { (between- } \\
\text { group } \\
\text { comparison) }\end{array}$ \\
\hline \multicolumn{6}{|l|}{ Weight } \\
\hline Control & $55.9 \pm 9.9$ & $54.9 \pm 9.2$ & $-1.0 \pm 2.4$ & $<0.001$ & \multirow[t]{2}{*}{0.880} \\
\hline Intervention & $55.8 \pm 9.2$ & $54.8 \pm 9.2$ & $-1.0 \pm 3.2$ & $<0.001$ & \\
\hline \multicolumn{6}{|l|}{ SBP } \\
\hline Control & $124.5 \pm 17.4$ & $123.6 \pm 14.6$ & $-0.9 \pm 17.2$ & 0.478 & \multirow[t]{2}{*}{0.115} \\
\hline Intervention & $123.5 \pm 15.5$ & $119.8 \pm 12.3$ & $-3.7 \pm 16.3$ & 0.003 & \\
\hline \multicolumn{6}{|c|}{ SBP in patients with $\mathrm{SBP} \geq 140 \mathrm{mmHg}$ and/or $\mathrm{DBP} \geq 90 \mathrm{mmHg}$ at baseline } \\
\hline Control & $145.1 \pm 11.4$ & $131.2 \pm 19.7$ & $13.9 \pm 14.9$ & $<0.001$ & \multirow[t]{2}{*}{0.029} \\
\hline Intervention & $148.8 \pm 10.4$ & $127.4 \pm 12.6$ & $-21.5 \pm 16.2$ & $<0.001$ & \\
\hline
\end{tabular}

a Paired Student's $t$ test

b Student's $t$ test

The education sessions were successful at improving the level of knowledge in the majority of participants in the intervention group. When starting the study, the proportion of patients achieving the target MDKT score, i.e., total score $\geq 11$ (average or good), was $37.4 \%$ in the intervention group and $35.2 \%$ in the control group. After 3 months of follow-up, the proportion of successful scores (average or good) had increased significantly to $81.3 \%$ in the intervention group and to $51.7 \%$ in the control group. The rate of success at 3 months was significantly higher in the intervention group compared to the control group (betweengroup difference $P<0.001$ ) (Fig. 2).

\section{HbA1c}

At the 3-month follow-up, there was a significant decrease in mean HbA1c in the intervention group from $8.09 \pm 1.85 \%$ to $7.56 \pm 1.64 \%$ (intra-group comparison $P<0.001$ ) compared with a non-significant decrease in the control group from $8.32 \pm 1.99 \%$ to $8.15 \pm 1.80 \%$ (Table 3). Mean changes from baseline HbA1c were $-0.54 \pm 1.41 \%$ and $-0.18 \pm 1.33 \%$ in the intervention and control groups, respectively. The estimate (SD) of the difference between the intervention and control groups was 0.36 (1.37), 95\% CI $0.08-0.64$ and the between-group difference in change in HbA1c at 3 months was significant $(P=0.012)$. The intervention was effective at significantly reducing HbA1c levels in both insulin-treated and noninsulin-treated subgroups with the betweengroup comparison reaching significance in the insulin-treated subgroup $(P=0.011$, Table 3$)$.

When considering the subgroup of patients with poor glycemic control (HbA1c $\geq 7 \%$ ) at baseline, mean changes in HbA1c from baseline were $-0.80 \pm 1.52 \%$ vs $0.41 \pm 1.47 \%$, respectively, in the intervention and control groups (between-group difference $P=0.013$ ). In contrast, there was no relevant intervention impact on HbA1c evolution in the subgroup of individuals with a baseline value $<7 \%$. The intervention was also effective at reducing $\mathrm{HbA1c}$ in both insulin- and non-insulin treated subgroups with $\mathrm{HbA} 1 \mathrm{c} \geq 7 \%$ at baseline. In patients on insulin, mean HbA1c reductions were $-1.49 \pm 2.14$ (vs $-0.32 \pm 1.46$ on control; $P=0.035$ with Student's $t$ test and 0.061 with Wilcoxon test). For patients not on insulin, reductions were $\quad-0.67 \pm 1.34 \quad$ (vs $-0.43 \pm 1.48$ on control; $P=0.221$ with Student's $t$ test and 0.052 with Wilcoxon test). 


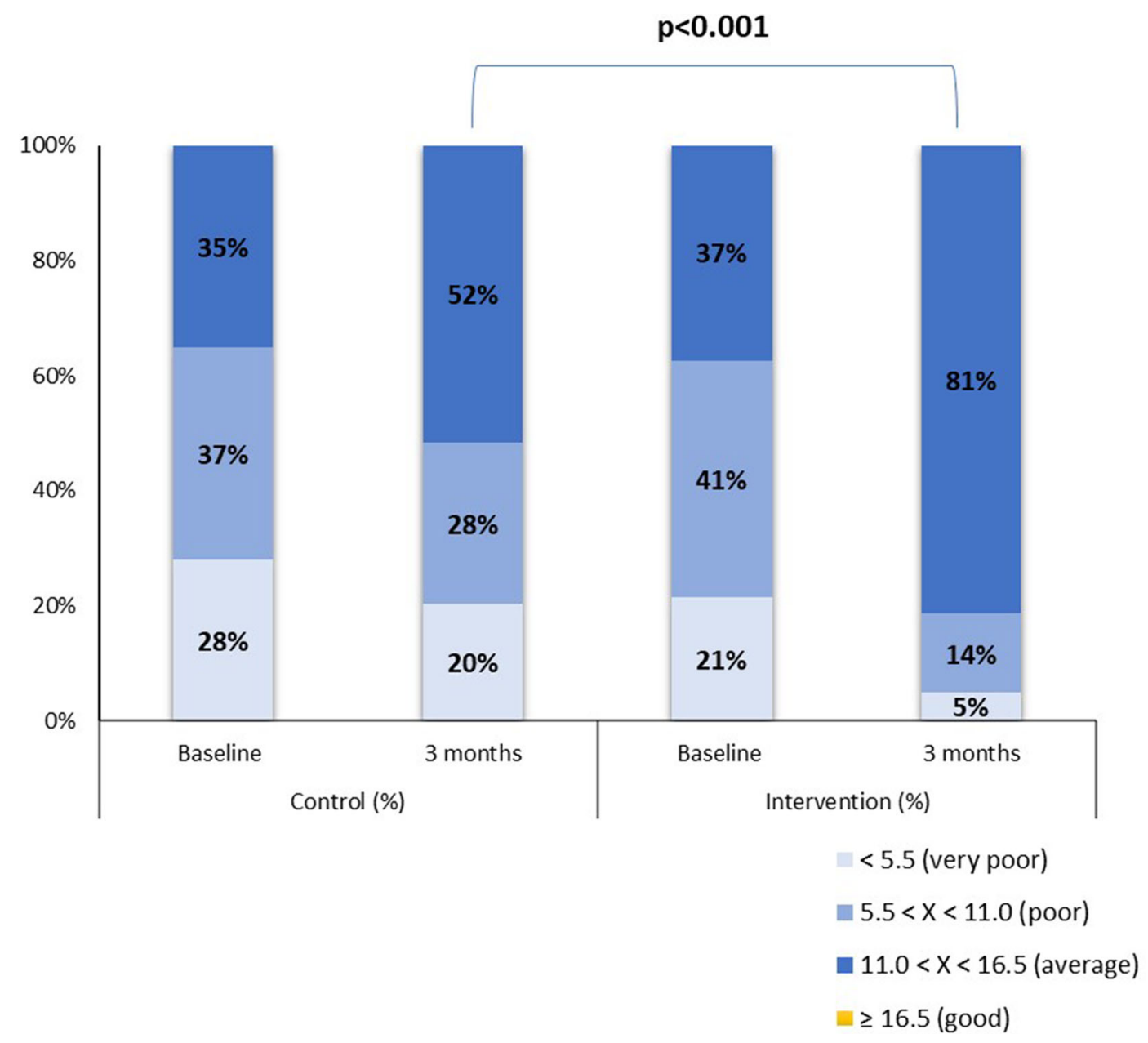

Fig. 2 Proportion of patients by category of Michigan University Diabetes Knowledge Test total score at baseline and after 3 months in the intervention and control groups

Numbers of patients were too small for analyses of effects of control and intervention in insulinand non-insulin treated patients with baseline $\mathrm{HbA} 1 \mathrm{c}<7 \%$.

The distribution of patients according to HbA1c ranges by randomization group at baseline and 3 months is shown in Fig. 3 . The proportion of patients whose HbA1c was controlled $(<7.0 \%)$ changed from $29.1 \%$ at baseline to $46.7 \%$ at 3 months in the intervention group, an increase of $17.6 \%$ (32 subjects whose HbA1c was uncontrolled at baseline achieved glycemic control at 3 months). In contrast, the proportion controlled in the usual care group remained essentially the same at $30.8 \%$ at baseline versus $29.1 \%$ at 3 months. The proportion of patients with $\mathrm{HbA} 1 \mathrm{c}<7 \%$ at
$(P<0.001$, Chi-square test for independence between Michigan total score and intervention/control groups)

3 months was significantly higher in the intervention group than in the control group in both the total population $(P<0.001)$ and the noninsulin treated subgroup $(P=0.002)$. In the insulin-treated subgroup, the number of patients with $\mathrm{HbA1c}<7 \%$ at 3 months was increased, but did not reach statistical significance because of the small numbers of patients involved.

\section{Fasting Plasma Glucose}

FPG was also decreased at 3 months from $8.95 \pm 2.82$ to $7.90 \pm 2.03 \mathrm{mmol} / \mathrm{L}$ in the intervention group and from $8.72 \pm 2.66$ to $8.49 \pm 2.53 \mathrm{mmol} / \mathrm{L}$ in the control group, with 


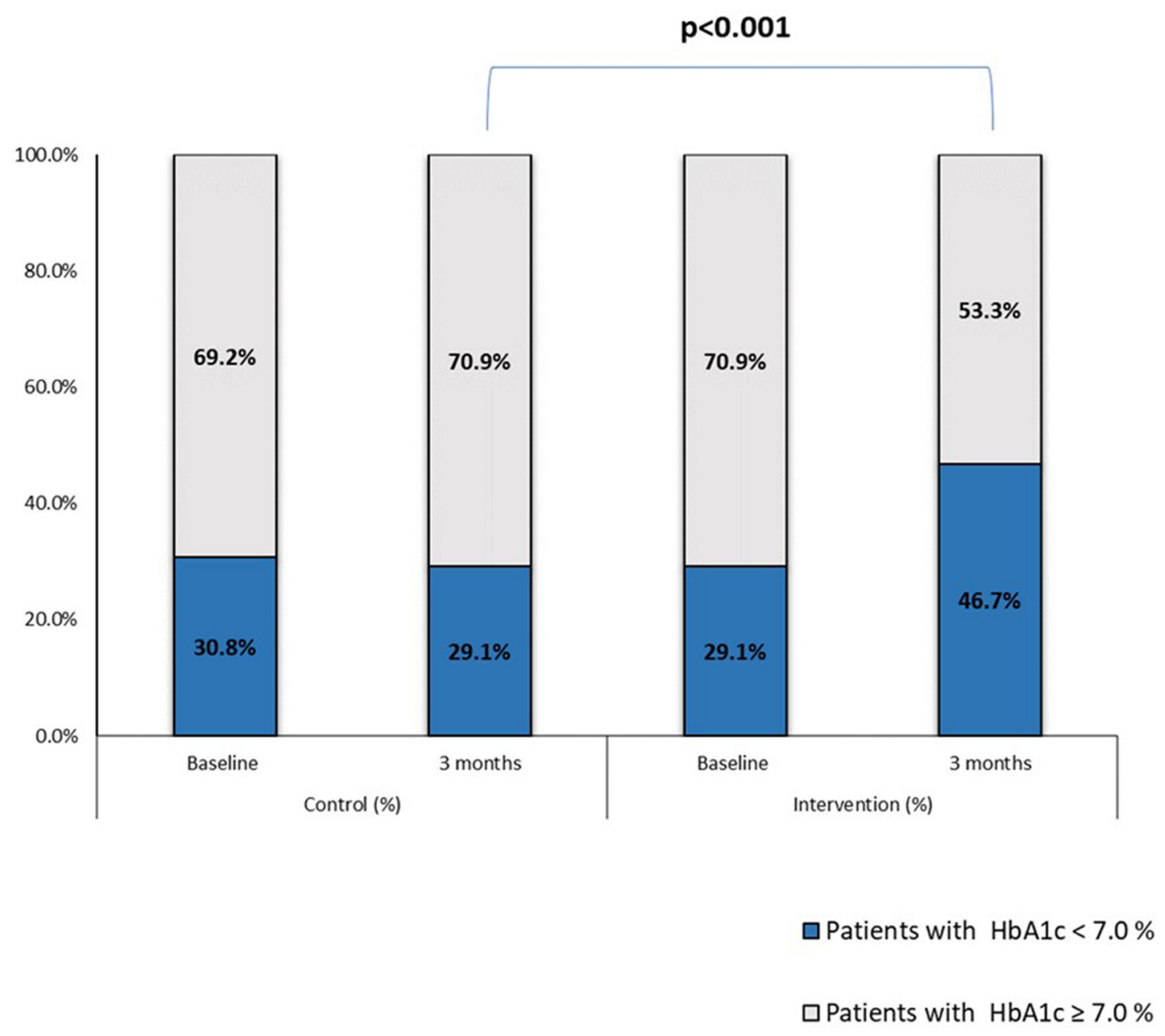

Fig. 3 Proportion of patients according to HbAlc category at baseline and 3 months in the intervention and control groups $(P<0.001$, Chi-square test for independence between HbAlc category and intervention/control groups)

the decrease only reaching significance in the intervention group (intra-group comparison $P<0.001)$. Mean changes from baseline FPG were $\quad-1.04 \pm 2.57 \mathrm{mmol} / \mathrm{L} \quad$ and $-0.23 \pm 2.14 \mathrm{mmol} / \mathrm{L}$ in the intervention and control groups, respectively. The estimate (SD) of the difference between the intervention and control groups was 0.81 (2.36), 95\% CI $0.32-1.30$ and the between-group difference in change in FPG at 3 months was significant $(P=0.001)$.

\section{Weight}

No significant effect of the intervention was observed on weight at 3 months of follow-up (Table 3). Mean weight decreased by $1 \mathrm{~kg}$ in both groups. In obese patients (BMI $>23 \mathrm{~kg}$ / $\mathrm{m}^{2}$ ), the mean decrease in weight was slightly higher but not significantly different between groups ( -1.6 and $-1.8 \mathrm{~kg}$, respectively, in the control and intervention groups).

\section{Blood Pressure and Lipids}

In the intervention group there was a significant reduction in systolic blood pressure at 3 months from a mean of $123.5 \pm 15.5 \mathrm{mmHg}$ at baseline to $119.8 \pm 12.3 \mathrm{mmHg}$ at 3 months (intra-group comparison $P=0.003$ ) (Table 3). No relevant changes in mean SBP were observed in the control group. Mean changes from baseline in the intervention and control groups were $-3.7 \pm 16.3$ and $\quad-0.9 \pm 17.2 \mathrm{mmHg}$, 
respectively; the difference between groups did not reach statistical significance. In both groups, reductions in blood pressure were more pronounced in those with values $\geq 140$ / $90 \mathrm{mmHg}$ at baseline, but significantly greater in the intervention group $(P=0.029)$ (Table 3$)$. Small improvements in lipid parameters were observed, but did not differ significantly between groups.

\section{Factors Influencing Blood Glucose Control}

Variables shown by univariate analysis to significantly influence the transition to blood glucose control (HbA1c $<7 \%)$ were study group (control vs intervention, $P<0.001$ ), HbA1c at baseline ( $<7 \%$ vs $\geq 7 \%, P=0.006)$, and diabetes duration $(P=0.029)$. Fasting blood glucose, insulin, and baseline MDKT score did not reach statistical significance, but met the 0.2 significance level cutoff required for entry into the multivariate analysis.

Multivariate analysis showed that variables influencing blood glucose control in this study were study group (OR 3.78, 95\% CI 1.82, 7.85, $P=0.0004)$, MDKT score (OR 1.99, 95\% CI 1.00 , 3.93, $P=0.0489$ ), diabetes duration (OR 0.86 , 95\% CI $0.75,0.98, P=0.0240$ ), and baseline HbA1c (OR 0.74, 95\% CI 0.58, 0.94, $P=0.0156)$.

\section{DISCUSSION}

The current study provides data to support the value of community education intervention as an adjunct to antidiabetes therapy in Vietnamese patients with type 2 diabetes, a region in which there is currently a lack of knowledge concerning the optimal lifestyle intervention programs in type 2 diabetes to ensure both adherence as well as long-term health outcomes [10]. In patients randomized to the intervention group, three 45-min sessions of additional group education and support resulted in significantly improved disease awareness and glycemic and blood pressure control in a population with a wide range of disease severity. Baseline HbA1c is a predictor of $\mathrm{HbA1c}$ change in patients responding to treatment $[36,37]$, and in line with other studies the greatest overall decrease in HbA1c was observed in the insulin-treated subgroup, who were also the most poorly controlled at baseline.

Results of the multiple logistic regression analysis suggested that patients most likely to benefit from the program and achieve blood glucose control were those who already had a certain level of knowledge of their disease, who had a shorter duration of illness, and a lower baseline HbA1c. It is possible that in patients with less knowledge of the disease and more severe diabetes, a longer period of education may be required to see improvement. Educational interventions may also be less effective in terms of blood glucose control in individuals with marked beta cell dysfunction, but should still be maintained to preserve remaining function and reduce cardiovascular disease risk factors [38].

Strict glycemic control is associated with a reduced risk of diabetes-related complications, particularly in those who have not suffered years of uncontrolled HbA1c levels [39]. Early achievement and maintenance of near-normal glycemia from the time of diagnosis is therefore essential for optimal outcomes. While the duration of this study was relatively short (3 months), the reductions in HbA1c of $-0.5 \%$ overall and $-0.8 \%$ in the subgroup uncontrolled at baseline (HbA1c $\geq 7 \%)$ would be clinically meaningful if sustained over the long term for reducing the risk of diabetes complications, particularly in patients with lower baseline values. An HbA1c reduction of $0.5 \%$ is considered clinically significant by guidelines for the management of type 2 diabetes [30, 40] and the US Food and Drug Administration accepts a non-inferiority margin for HbA1c change from baseline of $0.3 \%$ or $0.4 \%$ [ 41 ].

The HbA1c reductions were also supported by concomitant reductions in FPG that again reached significance in the intervention group. Studies have reported that strict blood glucose control can delay or prevent the progression of complications associated with diabetes [42-44]. Indeed, projections from the observational United Kingdom Prospective Diabetes Study (UKPDS 35) suggested that for each 1\% reduction in mean $\mathrm{HbA} 1 \mathrm{c}$ there would be an associated $14 \%$ lower rate of fatal and non-fatal 
myocardial infarction and death from any cause, $21 \%$ lower rate of death related to diabetes, and $37 \%$ reduction in the risk of microvascular complications [44]. The types of antidiabetes therapy the patients were receiving were evenly distributed between the intervention and control groups and the regimens were not altered for the duration of the study. Any observed differences in HbA1c between the groups can therefore be attributed to the intervention and not because of differences in study medication.

In the current study, well over half the participants (55.0\%) had a baseline HbA1c $\geq 7.0 \%$ despite treatment, a figure that is in line with data from the Vietnamese cohort of the DiabCare Asia observational study which reported that $63.9 \%$ of patients receiving treatment for type 2 diabetes for at least 1 year did not meet the ADA recommended HbA1c target of $<7.0 \%$ $(<53 \mathrm{mmol} / \mathrm{mol})$ [45].

A major factor limiting the efficacy of current diabetes management is a lack of patient education. A population-based survey conducted in a largely rural area in central Vietnam in 2014 reported that more than two-thirds of the 480 participants did not understand or had never heard of type 2 diabetes, and less than half of those diagnosed had reported a history of type 2 diabetes [46]. As the vast majority of day-to-day care in type 2 diabetes is managed by patients and their families, education is therefore urgently required, particularly in rural areas where levels of education are the lowest and access to quality medication is the most restricted.

While DSME programs are well integrated in Western developed countries [10], Vietnam's healthcare system, like that of many in developing countries, was designed to deliver acute care, and until recently did not typically include patient education. As a result, there is a paucity of studies on diabetes education in patients in developing countries [12]. With the current epidemic of type 2 diabetes this is now changing and the Vietnamese government has put in place a national strategy for non-communicable diseases for 2015-2025 that includes the control and prevention of diabetes [47]. Diabetes education is an important component of this strategy, and must result in long-term behavioral changes in the patient to be of value. Examples include following a diet plan; avoiding high-fat foods; reducing consumption of white rice, a food with a high glycemic index and a staple part of the Vietnamese diet; increasing levels of physical activity; self-monitoring of blood glucose; and foot care [48]. While decreasing an individual's HbA1c level may be the ultimate goal of diabetes self-management, it is not the only objective. Health promotion, and especially promotion of behavioral change towards a healthy diet and physical activity, are important interventions, with low costs in the management of type 2 diabetes and will also benefit other comorbid conditions such as obesity and hypertension [48]. The results of the current study demonstrate that this is possible with community group education sessions. After only 3 months, $81.3 \%$ of patients in the intervention group compared with $51.6 \%$ of patients in the control group passed the diabetes knowledge test.

The intervention was also associated with a significant reduction in SBP. Recent epidemiological data from Vietnam in individuals aged 25 years or older reported hypertension in $29 \%$ of those surveyed [49]. Furthermore, among those receiving antihypertensive drugs, 38\% had blood pressure levels that were not controlled. Vietnamese hypertension guidelines recognize the need to reduce blood pressure levels population wide [32]. Reductions in SBP and DBP of at least $2 \mathrm{mmHg}$ have been shown to significantly reduce the incidence of cardiovascular disease in both hypertensive and normotensive individuals [50], and therefore the blood pressure reductions achieved in the current study are considered clinically meaningful. While the effects of the intervention on lipid parameters and BMI did not reach significance, a longer study duration may have been required to demonstrate these effects. In this study, 70\% of the population were farmers, an occupation with moderate to intensive levels of physical activity, making it difficult to observe changes in weight over a short period of time.

As a result of its chronic nature, the severity of its complications and the means required to control them, type 2 diabetes is a costly disease 
not only for the affected individual and their family but also for the health authorities. Reductions of HbA1c have been systematically associated with healthcare cost reductions [51]. This underlines the importance of achieving lower HbA1c levels, particularly in uncontrolled patients, in countries with limited economic resources. Any costs of educational intervention sessions must therefore be weighed against the potential reduction in long-term complications and associated treatment costs that can be achieved with improved blood glucose control.

A meta-analysis of the effect of self-management education for adults with type 2 diabetes on glycemic control, which included 31 randomized controlled trials, found that the intervention decreased $\mathrm{HbA} 1 \mathrm{c}$ by $0.76 \%$ (95\% CI 0.34-1.18) more than the control group at immediate follow-up, but that the benefit declined 1-3 months after the intervention ceased [52]. Therefore, provision should also be made for periodic reinforcement to maintain behavioral changes in the long term.

Most research on the value of education and lifestyle intervention in type 2 diabetes is from developed countries, and there is an urgent need for this to be extended to low- to middleincome countries who are now experiencing the greatest increases in type 2 diabetes [53]. Previous studies have also called for further research into the efficiency of various health-promoting strategies in a Vietnamese context $[18,19]$. The current research goes some way to fulfilling this need, providing important data on the value of interventions to improve patient education in Vietnam and demonstrating that improvements in blood glucose control are achievable after only 3 months of intervention.

\section{Strengths and Limitations}

A strength of this study was that it provided practical experience on the effectiveness of diabetes health education in routine clinical practice in a country where a large proportion of the inhabitants have a relatively low level of education and poor economic status. Such a patient-centered approach to increase diabetes knowledge is likely to increase adherence to diabetes self-management programs. Baseline imbalance and confounding bias may occur despite randomization. However, given the large sample size and similar baseline characteristics of the two groups, the observed differences in patients' diabetes health-related knowledge and the small improvements in HbA1c in the intervention group after only 3 months of follow-up were likely related to the intervention rather than confounding factors. These findings therefore warrant further investigation in a larger trial to determine the HbA1c reductions that can be achieved and whether these can be maintained long term.

In line with most studies that have evaluated diabetes education programs, the study was open to all patients with diabetes who could benefit from the education, and not restricted to those newly diagnosed. A recent systematic review of studies that implemented DSME programs within 12 months of the initial type 2 diabetes diagnosis reported a small but statistically significant improvement in HbA1c $(-0.21 \%)$ compared with usual care [54]. It is possible that the difference was small because people with newly diagnosed type 2 diabetes are more likely to engage in behavioral changes following diagnosis regardless of whether or not they participate in an educational program [55]. The potential benefits of early patient education may also be long term, and evaluation and follow-up of the Ngaydautien project in newly diagnosed patients who have received little or no prior self-management education will be an important avenue for future research.

A limitation of this study was that it was restricted to a single hospital. The local population and their lifestyles may therefore not be reflective of the general Vietnamese population. As participants lived locally and attended the same hospital, information on the intervention could have been shared between the two randomization groups. Such "indirect" education could have influenced the behavior of individuals in the control group and thus limited the differences observed between the two randomization groups. The MDKT was adapted for the Vietnamese population on the basis of a pilot conducted in 10 Vietnamese individuals with type 2 diabetes. To date the modified 
questionnaire has not been formally validated in a Vietnamese population, but its reliability and validity have been demonstrated in Western populations [16]. A further limitation was that data on adherence to treatments were not collected.

\section{CONCLUSIONS}

Data from Vietnam show that a structured, group-based educational intervention for people with type 2 diabetes can significantly increase disease knowledge and improve levels of blood glucose control. Larger studies are now warranted in a more varied Vietnamese population to assess the benefits of diabetes education on patient behavior, adherence to drug therapy, and glucose control long term.

\section{ACKNOWLEDGEMENTS}

The authors thank all the participants of the study.

Funding. The authors acknowledge Servier Vietnam for support and funding of community intervention initiatives associated with the Ngaydautien project. Servier Vietnam involvement in the current study was limited to funding of editorial assistance and the publication Rapid Service Fee. Servier Vietnam had no role in study design and data collection.

Medical Writing and Statistical Analyses. Editorial assistance was provided by Jenny Grice on a freelance basis and funded by Servier. Statistical analyses were performed by Keyrus International and funded by Servier.

Authorship. All named authors meet the International Committee of Medical Journal Editors (ICMJE) criteria for authorship for this article, take responsibility for the integrity of the work as a whole, and have given their approval for this version to be published.
Authors' Contributions. All named authors were responsible for manuscript concept and design, and drafting of the manuscript.

Disclosures. Dr Thanh Ho and Tien Tran declare that the research was conducted in the absence of any commercial or financial relationships that could be construed as a potential conflict of interest. This article does not contain any studies with human subjects performed by any other authors.

Compliance with Ethics Guidelines. The study protocol was approved by the independent local Institutional Review Board of Thach That General Hospital and Hanoi Medical University, Hanoi. The studies involving human participants were reviewed and approved by IRB VN 01001 (Hanoi Medical University Ethic Committee) No. IRB 00003121. The trial was registered through the https:// clinicaltrials.gov site with the following identifier: NCT04403841. The trial was performed in accordance with the Helsinki Declaration of 1964 and its later amendments. Written informed consent for participation in this study was obtained from all participants.

Data Availability. The datasets generated and/or analyzed for this study are available from the corresponding author upon reasonable request.

Open Access. This article is licensed under a Creative Commons Attribution-NonCommercial 4.0 International License, which permits any non-commercial use, sharing, adaptation, distribution and reproduction in any medium or format, as long as you give appropriate credit to the original author(s) and the source, provide a link to the Creative Commons licence, and indicate if changes were made. The images or other third party material in this article are included in the article's Creative Commons licence, unless indicated otherwise in a credit line to the material. If material is not included in the article's Creative Commons licence and your intended use is not permitted by statutory regulation or exceeds the permitted use, you will need to obtain permission directly from the 
copyright holder. To view a copy of this licence, visit http://creativecommons.org/licenses/by$\mathrm{nc} / 4.0 /$.

\section{REFERENCES}

1. Nguyen CT, Pham NM, Lee AH, Binns CW. Prevalence of and risk factors for type 2 diabetes mellitus in Vietnam: a systematic review. Asia Pac J Public Health. 2015;27:588-600.

2. Pham NM, Eggleston K. Diabetes prevalence and risk factors among Vietnamese adults: findings from community-based screening programs. Diabetes Care. 2015;38:e77-8.

3. Hills AP, Arena R, Khunti K, et al. Epidemiology and determinants of type 2 diabetes in south Asia. Lancet Diabetes Endocrinol. 2018;6:966-78.

4. Nguyen TT, Hoang MV. Non-communicable diseases, food and nutrition in Vietnam from 1975 to 2015: the burden and national response. Asia Pac J Clin Nutr. 2018;27:19-28.

5. Guariguata L, Whiting DR, Hambleton I, Beagley J, Linnenkamp U, Shaw JE. Global estimates of diabetes prevalence for 2013 and projections for 2035 . Diabetes Res Clin Pract. 2014;103:137-49.

6. International Diabetes Federation. IDF Diabetes Atlas. Ninth edition (2019). https://diabetesatlas. org/upload/resources/material/20200106_152211_ IDFATLAS9e-final-web.pdf. Accessed 9 Jan 2020.

7. Pham NM, Eggleston K. Prevalence and determinants of diabetes and prediabetes among Vietnamese adults. Diabetes Res Clin Pract. 2016;113: 116-24.

8. Steinsbekk A, Rygg LØ, Lisulo M, Rise MB, Fretheim A. Group based diabetes self-management education compared to routine treatment for people with type 2 diabetes mellitus: a systematic review with meta-analysis. BMC Health Serv Res. 2012;12:213.

9. Chrvala CA, Sherr D, Lipman RD. Diabetes selfmanagement education for adults with type 2 diabetes mellitus: a systematic review of the effect on glycemic control. Patient Educ Couns. 2016;99: 926-43.

10. Mohamed A, Staite E, Ismail K, Winkley K. A systematic review of diabetes self-management education interventions for people with type 2 diabetes mellitus in the Asian Western Pacific (AWP) region. Nurs Open. 2019;6:1424-37.
11. Mikhael EM, Hassali MA, Hussain SA. Effectiveness of diabetes self-management educational programs for type 2 diabetes mellitus patients in Middle East countries: a systematic review. Diabetes Metab Syndr Obes. 2020;13:117-38.

12. Bekele BB, Negash S, Bogale B, et al. Effect of diabetes self-management education (DSME) on glycated hemoglobin (HbA1c) level among patients with T2DM: systematic review and meta-analysis of randomized controlled trials. Diabetes Metab Syndr. 2021;5:177-85.

13. Al-Khawaldeh OA, Al-Jaradeen N. Diabetes awareness and diabetes risk reduction behaviors among attendance of primary healthcare centers. Diabetes Metab Syndr. 2013;7:172-8.

14. Binh TQ, Phuong PT, Nhung BT. Knowledge and associated factors towards type 2 diabetes among a rural population in the Red River Delta region Vietnam. Rural Remote Health. 2015;15:3275.

15. Agarwal G, Angeles RN, Dolovich L, et al. The Community Health Assessment Program in the Philippines (CHAP-P) diabetes health promotion program for low- to middle-income countries: study protocol for a cluster randomized controlled trial. BMC Public Health. 2019;19:682.

16. do Valle Nascimento TM, Resnicow K, Nery M, et al. A pilot study of a community health agent-led type 2 diabetes self-management program using Motivational Interviewing-based approaches in a public primary care center in São Paulo Brazil. BMC Health Serv Res. 2017;17:32.

17. Afable A, Karingula NS. Evidence based review of type 2 diabetes prevention and management in low and middle income countries. World J Diabetes. 2016;7:209-29.

18. Pham L, Ziegert K. Ways of promoting health to patients with diabetes and chronic kidney disease from a nursing perspective in Vietnam: a phenomenographic study. Int J Qual Stud Health WellBeing. 2016;11:30722.

19. Baumann LC, Blobner D, Binh TV, Lan PT. A training program for diabetes care in Vietnam. Diabetes Educ. 2006;32:189-94.

20. American Diabetes Association. Classification and diagnosis of diabetes. Diabetes Care. 2015;38(Suppl 1):S8-16.

21. Fitzgerald JT, Funnell MM, Anderson RM, Nwankwo R, Stansfield RB, Piatt GA. Validation of the Revised Brief Diabetes Knowledge Test (DKT2). Diabetes Educ. 2016;42:178-87. 
22. Fitzgerald JT, Funnell MM, Hess GE, et al. The reliability and validity of a brief diabetes knowledge test. Diabetes Care. 1998;21:706-10.

23. Montagut-Martínez P, Pérez-Cruzado D, GutiérrezSánchez D. The dietary knowledge measurement instruments in diabetes: a systematic psychometric review. J Adv Nurs. 2021. https://doi.org/10.1111/ jan.14762.

24. Murata GH, Shah JH, Adam KD, et al. Factors affecting diabetes knowledge in type 2 diabetic veterans. Diabetologia. 2003;46:1170-8.

25. Jasper US, Ogundunmade BG, Opara MC, Akinrolie $\mathrm{O}$, Pyiki EB, Umar A. Determinants of diabetes knowledge in a cohort of Nigerian diabetics. J Diabetes Metab Disord. 2014;13:39.

26. Hashim MJ, Mustafa H, Ali H. Knowledge of diabetes among patients in the United Arab Emirates and trends since 2001: a study using the Michigan Diabetes Knowledge Test. East Mediterr Health J. 2017;22:742-8.

27. AlShayban DM, Naqvi AA, Alhumaid O, et al. Association of disease knowledge and medication adherence among out-patients with type 2 diabetes mellitus in Khobar Saudi Arabia. Front Pharmacol. 2020;11:60.

28. Al-Qazaz HKh, Sulaiman SA, Hassali MA, et al. Diabetes knowledge, medication adherence and glycemic control among patients with type 2 diabetes. Int J Clin Pharm. 2011;33:1028-35.

29. American Diabetes Association. Diabetes advocacy: standards of medical care in diabetes 2018. Diabetes Care. 2018;41(Suppl 1):S152-3.

30. Davies MJ, D'Alessio DA, Fradkin J, Management of hyperglycemia in type 2 diabetes, et al. A consensus report by the American Diabetes Association (ADA) and the European Association for the Study of Diabetes (EASD). Diabetes Care. 2018;2018(41): 2669-701.

31. Aschner P. New IDF clinical practice recommendations for managing type 2 diabetes in primary care. Diabetes Res Clin Pract. 2017;132:169-70.

32. Van Huynh M, Nguyen Lan V, Van Huy T, et al. Asian management of hypertension: current status, home blood pressure, and specific concerns in Vietnam. J Clin Hypertens (Greenwich). 2020. https://doi.org/10.1111/jch.13780.

33. World Health Organization Western Pacific Region. The Asia-Pacific perspective: redefining obesity and its treatment. Health Communications Australia; Melbourne: 2000. https://apps.who.int/ iris/bitstream/handle/10665/206936/0957708211_ eng.pdf.

34. Fleiss JL, Tytun A, Ury HK. A simple approximation for calculating sample sizes for comparing independent proportions. Biometrics. 1980;36:343-6.

35. Ahn VTK, et al. Knowledge about diabetes and some related factors in DM patients in private medical centers, Binh Duong province Vietnam. Prevent Med J. 2015;XXV(N8):326.

36. DeFronzo RA, Stonehouse AH, Han J, Wintle ME. Relationship of baseline HbA1c and efficacy of current glucose-lowering therapies: a meta-analysis of randomized clinical trials. Diabet Med. 2010;27: 309-17.

37. Cantrell RA, Alatorre CI, Davis EJ, et al. A review of treatment response in type 2 diabetes: assessing the role of patient heterogeneity. Diabetes Obes Metab. 2010;12:845-57.

38. Marchetti P, Suleiman M, De Luca C, et al. A direct look at the dysfunction and pathology of the $\beta$ cells in human type 2 diabetes. Semin Cell Dev Biol. 2020;103:83-93.

39. Holman RR, Paul SK, Bethel MA, Matthews DR, Neil HA. 10-year follow-up of intensive glucose control in type 2 diabetes. N Engl J Med. 2008;359:1577-89.

40. National Institute for Health and Care Excellence. Type 2 diabetes in adults: management. NICE guideline Published: 2 December 2015. Last updated August 2019. https://www.nice.org.uk/ guidance/ng28.

41. Food and Drug Administration Center for Drug Evaluation and Research. Guidance for Industry. Diabetes mellitus: developing drugs and therapeutic biologics for treatment and prevention. Center for Drug Evaluation and Research. February 2008. https://www.fda.gov/media/71297/download.

42. Ohkubo Y, Kishikawa H, Araki E, et al. Intensive insulin therapy prevents the progression of diabetic microvascular complications in Japanese patients with non-insulin-dependent diabetes mellitus: a randomized prospective 6-year study. Diabetes Res Clin Pract. 1995;28:103-17.

43. UK Prospective Diabetes Study Group. Intensive blood-glucose control with sulphonylureas or insulin compared with conventional treatment and risk of complications in patients with type 2 diabetes (UKPDS 33). Lancet. 1998;352:837-53.

44. Stratton IM, Adler AI, Neil HA, et al. Association of glycaemia with macrovascular and microvascular complications of type 2 diabetes (UKPDS 35): a 
prospective observational study. BMJ. 2000;321: 405-12.

45. Nguyen KT, Diep BT, Nguyen VD, Lam HV, Tran KQ. A cross-sectional study to evaluate diabetes management, control and complications in 1631 patients with type 2 diabetes mellitus in Vietnam (DiabCare Asia). Int J Diabetes Dev Ctries. 2019. https://doi.org/10.1007/s13410-019-00755-w.

46. Miyakawa M, Shimizu T, Van Dat N, et al. Prevalence, perception and factors associated with diabetes mellitus among the adult population in central Vietnam: a population-based, cross-sectional seroepidemiological survey. BMC Public Health. 2017;17:298.

47. World Health Organization. Noncommunicable diseases progress monitor. Geneva: WHO; 2015.

48. Shrivastava SR, Shrivastava PS, Ramasamy J. Role of self-care in management of diabetes mellitus. J Diabetes Metab Disord. 2013;12(1):14.

49. Beaney T, Schutte AE, Tomaszewski M, et al. May measurement month 2017: an analysis of blood pressure screening results worldwide. Lancet Glob Health. 2018;6:e736-43.

50. Turnbull F, Blood Pressure Lowering Treatment Trialists' Collaboration. Effects of different bloodpressure-lowering regimens on major cardiovascular events: results of prospectively-designed overviews of randomised trials. Lancet. 2003;362: 1527-35.

51. Bansal M, Shah M, Reilly B, Willman S, Gill M, Kaufman FR. Impact of reducing glycated hemoglobin on healthcare costs among a population with uncontrolled diabetes. Appl Health Econ Health Policy. 2018;16:675-84.

52. Norris SL, Lau J, Smith SJ, Schmid CH, Engelgau MM. Self-management education for adults with type 2 diabetes: a meta-analysis of the effect on glycemic control. Diabetes Care. 2002;25:1159-71.

53. Lin $\mathrm{X}, \mathrm{Xu} \mathrm{Y}$, Pan $\mathrm{X}$, et al. Global, regional, and national burden and trend of diabetes in 195 countries and territories: an analysis from 1990 to 2025. Sci Rep. 2020;10(1):14790.

54. Tanaka R, Shibayama T, Sugimoto K, Hidaka K. Diabetes self-management education and support for adults with newly diagnosed type 2 diabetes mellitus: a systematic review and meta-analysis of randomized controlled trials. Diabetes Res Clin Pract. 2020;169:108480.

55. Davies MJ, Heller S, Skinner TC, et al. Effectiveness of the diabetes education and self management for ongoing and newly diagnosed (DESMOND) programme for people with newly diagnosed type 2 diabetes: cluster randomised controlled trial. BMJ. 2008;336:491-5. 